УДК: 657.471

DOI 10.18101/2304-4446-2020-3-59-66

\title{
ВНУТРИХОЗЯЙСТВЕННАЯ ОТЧЕТНОСТЬ СЕЛЬСКОХОЗЯЙСТВЕННЫХ ОРГАНИЗАЦИЙ В УСЛОВИЯХ ЦИФРОВИЗАЦИИ ЭКОНОМИКИ
}

\author{
(C) Тищенко Марина Анатольевна \\ кандидат экономических наук, доцент, \\ Красноярский государственный аграрный университет \\ Россия, 660049, г. Красноярск, пр. Мира, 90 \\ E-mail: mtischenko@mail.ru
}

В условиях цифровизации экономики повышаются возможности управленческого учета как источника информации для принятия управленческих решений. При этом возникает необходимость преобразования его инструментария, в частности, внутрихозяйственной отчетности, которая является базой для проведения оперативного контроля и анализа. Проведенные исследования показали, что в производственных подразделениях большинства сельскохозяйственных организаций Красноярского края оперативный контроль и анализ либо не проводятся вообще, либо сформированные отчеты перегружены нерелевантной информацией. Цифровизация аграрной экономики лишь усугубляет эту проблему - увеличивается поток информационных продуктов низкого качества, что вызывает отвлечение внимания руководства на анализ, по сути, ненужной информации. В статье предложено структурирование показателей внутренней отчетности в соответствующих формах в зависимости от уровня и цели управления. На примере отрасли животноводства предложено использование оперативных отчетов о расходе кормов и ежедневного выполнения плана по надою молока по молочно-товарной ферме, показаны их аналитические возможности. Предлагаемые отчеты как формы внутрихозяйственной отчетности позволят руководителям своевременно устранять недостатки в организации производства, рационально использовать материальные ресурсы, выявлять имеющиеся резервы и повышать эффективность производства. Использование информации внутрихозяйственной отчетности в условиях цифровизации урегулирует взаимодействие между информационной системой и пользователями и повысит качество принимаемых управленческих решений.

Ключевые слова: цифровизация; управленческий учет; релевантная информация; оперативный анализ; уровень управления, центр ответственности.

\section{Для цитирования}

Тищенко М. А. Внутрихозяйственная отчетность сельскохозяйственных организаций в условиях цифровизации экономики // Вестник Бурятского государственного университета. Экономика и менеджмент. 2020. № 3. С. 59-66.

В настоящее время новым этапом развития экономики в мире является цифровизация. В широком смысле цифровизация (от англ. — «digitalization») представляет собой повсеместное внедрение технологий, позволяющих сохранять, передавать и обрабатывать информацию в виде цифрового кода.

В России, согласно Прогнозу научно-технологического развития РФ на период до 2030 г., одной из приоритетных областей развития являются информационно-коммуникационные технологии. Им отведена роль ключевых драйверов перехода к цифровой экономике. Возникновение новых повсеместных, интерак- 
тивных, персонализированных, сверхскоростных сетей, устройств и систем глобального масштаба обусловливает развитие мультимедийного контента ${ }^{1}$.

Одной из целей национального проекта «Национальная программа «Цифровая экономика Российской Федерации» является создание устойчивой и безопасной информационно-телекоммуникационной инфраструктуры высокоскоростной передачи, обработки и хранения больших объемов данных, доступной для всех организаций и домохозяйств ${ }^{2}$. Таким образом, цифровизация касается всей системы информационного обеспечения социально-экономических процессов. В рамках отдельного экономического субъекта большое значение в этой системе имеет управленческий учет, осуществляющий сбор, обработку и предоставление информации о деятельности предприятия и его подразделений внутренним пользователям. В цифровой экономике возникает необходимость преобразования инструментария управленческого учета. При этом инструментарий должен обеспечить выполнение целей и задач управленческого учета (табл. 1).

В условиях цифровизации экономики управленческий учет имеет широкие возможности для осуществления эффективного процесса принятия управленческих решений на основе анализа обширных баз данных. Вместе с тем эти возможности, предоставляемые информационно-коммуникационными технологиями, а также необходимость решения задач управленческого учета, которые выходят за рамки только лишь учетного процесса, несут и определенные риски. Они связаны, прежде всего, с переизбытком получаемой учетной и неучетной (планов деятельности предприятия и его подразделений, данных об исполнении бюджетов, результаты факторного анализа отклонений и т. д.) информации. Особенно актуально это для сельскохозяйственных предприятий с их многообразием отраслей и производств, видов производимой продукции (выполняемых работ и оказываемых услуг).

В 2015 г. Институтом присяжных бухгалтеров в области управленческого учета (СIMA) и Американским институтом дипломированных бухгалтеров (AICPA) были изданы «Международные принципы управленческого учета», обновленные в соответствии с требованиями времени, которые учитывают актуальные проблемы переизбытка информации в современном мире, а также рассредоточения рабочей силы и стремительных изменений в экономике (рис. 1). При разработке положений были использованы результаты научных исследований, анализа информации о практической деятельности коммерческих организаций разных стран, публичных обсуждений, проходивших в течение 2014 г., и т. д. Российские эксперты также приняли участие в разработке обновленных принципов - предоставлялись комментарии и отзывы к проекту документа. А в марте 2014 г. в Москве состоялось заседание круглого стола, в результате которого финансовыми директорами международных и российских компаний, а так-

${ }^{1}$ Прогноз научно-технологического развития Российской Федерации на период до 2030 года: утвержден Правительством РФ 03.01.2014 // Гарант. URL: https://www.garant.ru/products/ipo/prime/doc/70484380/ (дата обращения: 14.01.2020).

2 Паспорт национального проекта «Национальная программа «Цифровая экономика Российской Федерации»: утв. Президиумом Совета при Президенте РФ по стратегическому развитию и национальным проектам, протокол от 24.12.2018 № 16 . URL: https://base.garant.ru/72190282/\#friends (дата обращения: 14.01.2020). 
М. А. Тищенко. Внутрихозяйственная отчетность сельскохозяйственных организаций в условиях цифровизации экономики

же научными работниками были даны рекомендации по содержанию проекта документа.

Таблица 1

Цель и задачи управленческого учета в современных условиях

\begin{tabular}{|c|c|}
\hline $\begin{array}{c}\text { Основные } \\
\text { характеристики }\end{array}$ & Содержание \\
\hline Цель & $\begin{array}{l}\text { обеспечение информацией руководства организации, менеджеров } \\
\text { различных уровней управления, ответственных за достижение кон- } \\
\text { кретных хозяйственных целей }\end{array}$ \\
\hline Задачи & $\begin{array}{l}\text { - обеспечение согласованного функционирования системы учета } \\
\text { затрат и доходов; } \\
\text { - нормирование затрат, бюджетирование (планирование) затрат; } \\
\text { - организация эффективной системы учета затрат по центрам от- } \\
\text { ветственности; } \\
\text { - обеспечение базы для ценообразования; } \\
\text { - контроль, планирование и прогнозирование экономической эф- } \\
\text { фективности деятельности предприятия и центров ответственности; } \\
\text { - выбор наиболее эффективных путей развития предприятия. }\end{array}$ \\
\hline
\end{tabular}

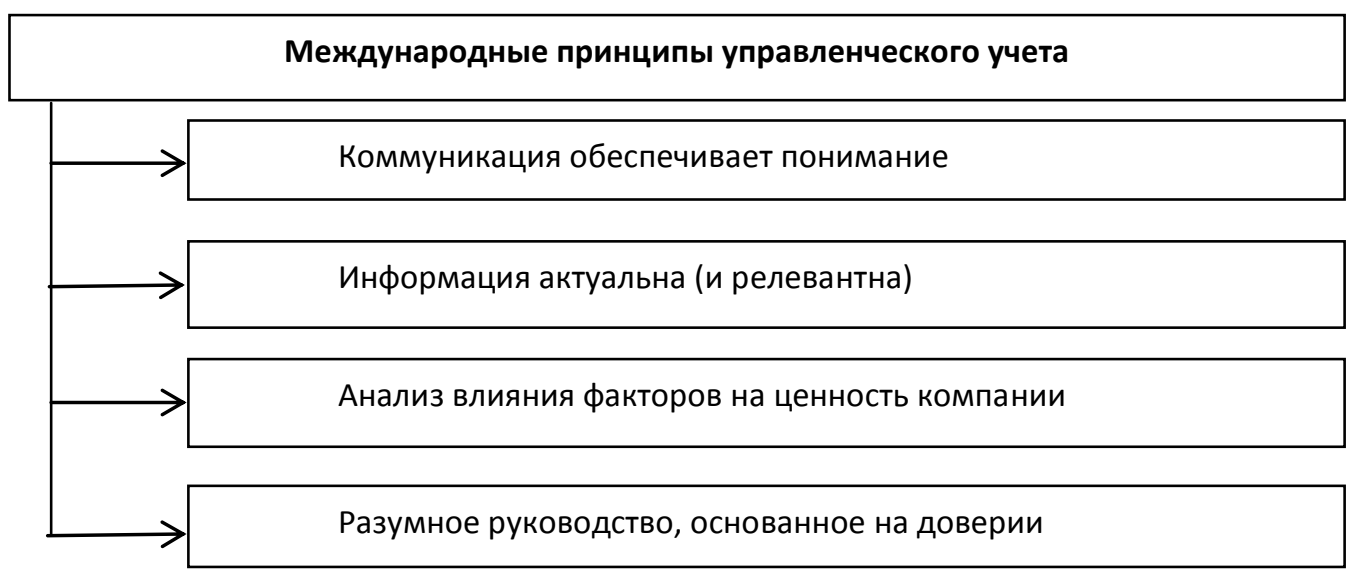

Рис. 1. Международные принципы управленческого учета

Международные принципы призваны оказать помощь организациям в выстраивании процесса принятия управленческих решений, повышении его эффективности. Следование принципам позволит устранить организационные барьеры путем установления эффективной коммуникации; выделять и использовать самую актуальную и надежную информацию для анализа; применять аналитические методы, позволяющие видеть воздействие различных факторов на стоимость организации; укрепить атмосферу добросовестности и доверия, что обеспечит развитие бизнеса в долгосрочной перспективе.

Проведенные теоретические исследования показали, что большинство отечественных авторов указывают на важность аналитической и контрольной функ- 
ций управленческого учета. При этом отмечается, что функции анализа и контроля невозможно выполнять без соответствующего информационного обеспечения $[1,2,7,9]$.

Как показывает практика, в большинстве сельскохозяйственных организаций эффективное осуществление контроля и анализа данных осложняется еще на уровне производственного подразделения. В некоторых случаях контроль и анализ показателей не осуществляются совсем, а там, где они проводятся, существующие формы отчетов перегружены нерелевантной информацией. В результате руководители подразделений могут реально измерять и управлять лишь некоторыми показателями, содержащимися в отчетах, остальные же лишь зря отвлекают их внимание.

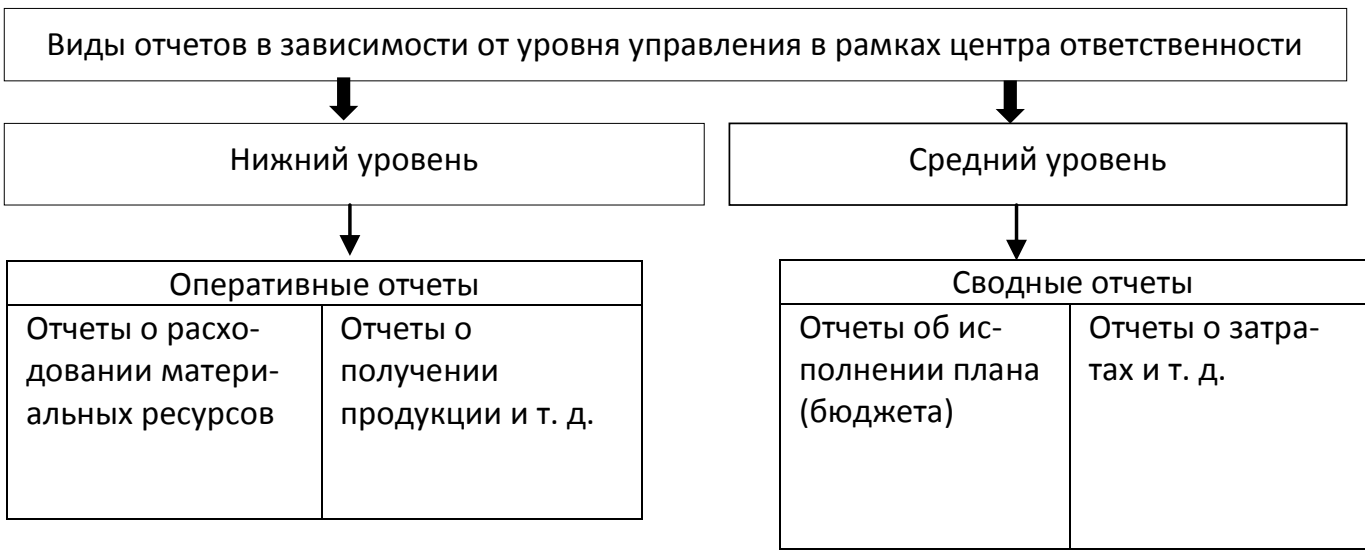

Рис. 2. Виды отчетов в зависимости от уровня управления

в рамках центра ответственности

Решить проблему выделения полезной информации из общего огромного потока поступающих данных и тем самым освобождения специалистов по управленческому учету от излишней работы, по нашему мнению, поможет структурирование внутренней информации с помощью внутрихозяйственной (внутренней сегментарной, управленческой) отчетности. В настоящее время порядок составления внутренней отчетности не отражен в действующих законодательных актах и нормативных документах. Поэтому составление внутренней отчетности является полностью прерогативой самой организации. Предприятию необходимо учитывать уровни управления в рамках центра ответственности для четкого и быстрого формирования внутренней отчетности по необходимым запросам руководства. В связи с этим внутрихозяйственные отчеты целесообразно формировать по подразделениям предприятия (центрам ответственности), включая в них необходимые показатели в зависимости от цели и уровня управления. Так, с нашей точки зрения, в зависимости от уровня управления внутри центра ответственности отчеты следует подразделить на оперативные и сводные (рис. 2). 
М. А. Тищенко. Внутрихозяйственная отчетность сельскохозяйственных организаций в условиях цифровизации экономики

Таблица 2

Отчет о расходе кормов на молочно-товарной ферме с 23 по 30 июня

\begin{tabular}{|l|c|c|c|c|c|}
\hline \multirow{2}{*}{ Показатели } & \multicolumn{5}{|c|}{ Виды кормов } \\
\cline { 2 - 6 } & комбикорм & сено & солома & силос & $\begin{array}{c}\text { зеленые } \\
\text { корма }\end{array}$ \\
\hline Расход кормов в натуре, ц: & & & & & \\
- план & 1,25 & 43 & 14 & 33 & 128 \\
- фактически & 1,4 & 41 & 16 & 36 & 123 \\
- отклонения от плана (+, -) & $+0,15$ & -2 & +2 & +3 & -5 \\
\hline Расход кормовых единиц, ц: & & & & & \\
- план & 1,25 & 17 & 2,8 & 10,6 & 24,6 \\
- фактически & 1,4 & 16,4 & 3,2 & 11,6 & 23,6 \\
- отклонения от плана (+,-) & $+0,15$ & $-0,6$ & $+0,4$ & +1 & -1 \\
\hline
\end{tabular}

Анализом информации оперативных отчетов занимаются руководители нижнего уровня управления. В производственных подразделениях сельскохозяйственных организаций к ним относятся бригадиры, начальники цехов, заведующие животноводческими фермами и т. д. Деятельность руководителей этого уровня характеризуется разнообразием действий, большой степенью коммуникации с подчиненными. Они призваны осуществлять контроль за выполнением производственных заданий, использованием выделенных подразделению ресурсов и т. д. Эти данные предлагается отражать в оперативных отчетах подразделения (отчеты о расходовании материальных ресурсов - их можно группировать по видам, отчеты о получении продукции и другие). Частота представления указанных отчетов может варьироваться от одного дня до двух недель.

Руководители среднего уровня возглавляют крупное подразделение в организации (заместитель руководителя по растениеводству, животноводству, бухгалтеры-аналитики подразделений). Характер их работы в большей степени определяется содержанием работы подразделения, чем организации в целом. Например, деятельность руководителя производства соответствующей отрасли в сельскохозяйственной организации включает координирование и управление работой руководителей нижнего звена, анализ данных о производительности труда и взаимодействия со специалистами. Руководители среднего уровня являются связующим звеном между руководителями высшего и нижнего уровней. Именно они формируют информацию на основании текущих отчетов для решений, принимаемых руководителями организации. И в дальнейшем передают решения руководства, как правило, после трансформации их в приемлемой форме в виде конкретных заданий руководителям нижнего уровня. Так, например, производственные подразделения в животноводстве следует определить как центры затрат (разновидность центров, ответственных за затраты своего подразделения [6]). Для оперативного контроля за расходованием материальных ресурсов по животноводческим фермам целесообразно формировать оперативные отчеты о расходе кормов и других материальных ценностей, о выходе продукции и т. д. Для текущего контроля, по нашему мнению, следует использовать отчеты об исполнении плана (бюджета) и отчеты о затратах, которые необходимо представлять в разрезе установленных статей. 
Важнейшим условием развития животноводства является обеспеченность животных и птицы кормами. Каждая организация должна стремиться полностью удовлетворять потребность в кормах, при этом оптимизируя затраты на их производство или приобретение со стороны. Рациональное использование кормов зависит от таких факторов, как организация кормления животных, питательности кормов (содержание кормовых единиц, переваримого протеина и сухого вещества), стоимости кормов. Плановые показатели для оперативного анализа использования кормов содержатся в производственных планах (операционных бюджетах подразделений) организации.

Используя данные о потребности в кормах, нормах расходов кормов на одну голову скота и на единицу продукции животноводства, можно проводить оперативный анализ обеспеченности животных кормами, соблюдения установленных норм расхода кормов и рационов кормления животных. При анализе учитывается питательность кормов. Отчет о расходе кормов, который предлагается использовать для оперативного анализа, представлен в таблице 2 . В анализируемом хозяйстве за последнюю неделю июня по сравнению с планом было израсходовано сена - меньше на 2 ц и зеленых кормов меньше на 5 ц. Уменьшение количества сена в рационе обусловлено его недостатком в организации. Это могло произойти в результате задержки сенокошения. Недостаток указанных кормов отразился и на расходе их в кормовых единицах: за исследуемый период скот недополучил 0,6 кормовых единиц по сену и $1-$ по зеленым кормам. Это, безусловно, привело к снижению продуктивности скота, невыполнению планов по надоям.

Как известно, продуктивность коров может варьировать каждый день под влиянием факторов, особенно, таких как качество кормов и ухода за животными. Следовательно, возникает необходимость оперативного контроля и анализа надоя молока в качестве эффективных методов влияния на результаты производства (табл. 3).

Таблица 3

Отчет ежедневного выполнения плана по надою молока на молочно-товарной ферме за июнь

\begin{tabular}{|c|c|c|c|c|c|c|c|c|c|c|}
\hline \multirow[t]{2}{*}{$\begin{array}{c}\text { Фамилии } \\
\text { доярок }\end{array}$} & \multirow[b]{2}{*}{ 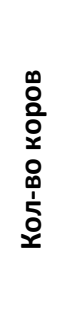 } & \multirow{2}{*}{ 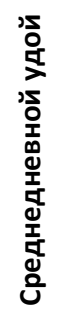 } & \multicolumn{6}{|c|}{ Надои молока по числам месяца, кг } & \multicolumn{2}{|c|}{$\begin{array}{c}\text { Bcero за июнь, } \\
\text { кг }\end{array}$} \\
\hline & & & 1 & 2 & 3 & 4 & 5 & $\begin{array}{c}\text { и } \\
\text { т. д. }\end{array}$ & план & факт \\
\hline Сазонова Т. П. & 16 & 280 & 282 & 285 & 280 & 278 & 275 & & 8680 & 8620 \\
\hline Ревенкова А. А. & 16 & 262 & 266 & 264 & 259 & 258 & 256 & & 8122 & 7990 \\
\hline Цветцых Т. И. & 16 & 280 & 281 & 283 & 280 & 285 & 286 & & 8680 & 8711 \\
\hline Гаврилкова И. В. & 16 & 280 & 280 & 279 & 281 & 276 & 276 & & 8680 & 8649 \\
\hline Микулич Е. Н. & 16 & 280 & 282 & 282 & 284 & 283 & 282 & & 8680 & 8773 \\
\hline Ромашенко Е. Л. & 16 & 290 & 290 & 291 & 293 & 293 & 294 & & 8990 & 9052 \\
\hline Терентьева 3. Е. & 16 & 280 & 282 & 285 & 285 & 286 & 286 & & 8680 & 8804 \\
\hline Итого & 112 & 279 & 1963 & 1969 & 1962 & 1959 & 1955 & & 51832 & 60599 \\
\hline
\end{tabular}


М. А. Тищенко. Внутрихозяйственная отчетность сельскохозяйственных организаций в условиях цифровизации экономики

Анализ результатов отчета ежедневного выполнения плана по надою молока на молочно-товарной ферме показал, что в июне четыре доярки выполнили план по надою молока, а три - не выполнили его. При одинаковом породном составе коров и достаточном их обеспечении кормами продуктивность животных зависит от качества ухода за ними. Проведенный анализ показал, что суточные надои по группе коров, закрепленных за дояркой Ромашенко Е. Л., значительно выше, чем по другим группам коров. Ромашенко Е. Л. достигла отличных результатов благодаря хорошему уходу за животными (породный состав, возраст, наследственные признаки продуктивности коров ее группы такие же, как и у коров, закрепленных за другими доярками).

Доярки Сазонова Т. П., Ревенкова А. А., Гаврилкова И. В. имеют возможность использовать положительный опыт работы лучших доярок Ромашенко Е. Л. и Терентьевой 3. Е., повысить производительность труда и внести определенный вклад в выполнение плана надоя молока по молочно-товарной ферме. В случае повышения надоев молока от каждой коровы на ферме до уровня, полученного дояркой Ромашенко Е. Л. - 565,7 кг (9052: 16), можно дополнительно получить 2759 кг молока $(565,7$ x 112 - 60599) и перевыполнить план за июнь на 5,3\% (2759 : 51832 х100). Это свидетельствует о том, что молочно-товарная ферма имеет достаточно резервов для выполнения и перевыполнения планов по надою молока.

Очевидно, что предлагаемые отчеты будут содержать лишь релевантную информацию, необходимую для принятия оперативных решений по эффективному использованию кормов, повышению продуктивности поголовья скота и другим показателям. К тому же данные будут предоставляться руководителям нижнего и среднего звеньев управления, которые могут оперативно влиять на сложившуюся ситуацию в производстве.

При формировании внутренних управленческих отчетов необходимо использовать технологические возможности цифровизации. В управленческом учете это выбор оптимального программного обеспечения для автоматизации учетных процессов.

Таким образом, использование предложенных форм внутренней управленческой отчетности, содержащих релевантную информацию, использование эффективного программного обеспечения, регулирование взаимодействия между информационной системой и пользователями, даст возможность своевременно устранять недостатки в организации производства, рационально использовать материальные ресурсы, выявлять имеющиеся резервы и повышать эффективность производства. Кроме того, при этом обеспечится выполнение таких требований к внутренней отчетности, как целесообразность, оперативность, адресность, эффективность [8]. Как следствие, повысится и качество принимаемых руководством решений, а значит, и эффективность деятельности всей организации в условиях цифровизации экономики.

\section{Литература}

1. Акаева А. С., Мусаев Т. К. Организация и методика внутреннего контроля учета затрат в молочном скотоводстве // Бухучет в сельском хозяйстве. 2019. № 8. С. 52-65.

2. Алборов Р. А., Хоружий Л. И. Организация учета затрат и продукции в молочном и мясном скотоводстве по модели управления производством «Затраты - выпуск - peзультат» // Бухучет в сельском хозяйстве. 2019. № 5. С.12-21. 
3. Алимова М. С. Особенности формирования форм управленческой отчетности о производственных затратах на промышленных предприятиях // Управленческий учет. 2019. № 5. C. 3-7.

4. Батуева Д. Д., Батуева О. Б. Функциональная системность учетно-аналитикоконтрольной информации // Вестник БГУ. Экономика и менеджмент. 2017. № 4. С. 7-17.

5. Булгатова Ю. С., Цыренов Д. Д. Разработка концептуальных положений использования блокчейн-технологий с целью повышения эффективности управления в экономических системах // Вестник БГУ. Экономика и менеджмент. 2018. № 4. С. 26-31.

6. Вахрушина М. А. Управленческий учет как современная учетная парадигма бюджетных учреждений // Учет. Анализ. Аудит. 2016. №1. С. 74-89.

7. Ибрагимова А. Х. Информационная база стратегического управленческого учета и контроллинга // Вестник Воронежского государственного аграрного университета. 2019. Т.12, № 3(62). С. 176-183.

8. Палий В. Ф. Управленческий учет издержек и доходов с элементами финансового учета. М.: ИНФРА-М, 2006. 279 с.

9. Широбоков В.Г., Проценко Р. А., Широбокова Н. В. Развитие теоретикометодических положений управленческого учета в молочном скотоводстве // Современное состояние и организационно-экономические проблемы развития АПК: материалы междунар. науч.-практ. конф., посвящ. 65-летию кафедры экономики АПК экономического факультета. Воронеж, 2019. С. 342-345.

\section{INTERNAL REPORTING OF AGRICULTURAL ORGANIZATIONS UNDER THE ECONOMY DIGITALIZATION}

Marina A. Tischenko

Cand. Sci. (Econ.), A/Prof.,

Krasnoyarsk State Agrarian University

90 Mira Prospect, Krasnoyarsk 660049, Russia

E-mail: mtischenko@mail.ru

The possibilities of management accounting as a source of information for making management decisions are increasing in the conditions of economy digitalization. At the same time, there is a need to transform its tools, in particular, internal reporting, which forms the basis for operational control and analysis. The studies have shown that in most sub-entities of agricultural organizations of Krasnoyarsk Krai there is no operational control and analysis at all or the reports created are overloaded with irrelevant information. The digitalization of agrarian economy only aggravates this problem: information products of low quality increases, and this distracts the managers' attention to the analysis of unnecessary information. The article proposes to structurize the internal reporting indicators according to the level and purpose of management. It is proposed to use operational reports in livestock section, such as a report on feed consumption and a report on completion of a plan for daily milk yield at commercial dairy farm. The proposed reports as a form of internal reporting enable managers to timely eliminate shortcomings in the organization of production, to use effectively material resources, as well as to identify reserves and increase production efficiency. The use of internal reporting under economy digitalization will regulate the interaction between the information system and users and will improve the quality of management decisions.

Keywords: digitalization; management accounting; relevant information; operational analysis; level of management, center of responsibility. 